\title{
Role of vitamin D deficiency in systemic lupus erythematosus incidence and aggravation
}

\author{
Tohid Hassanalilou $^{1}$ - Leila Khalili ${ }^{1}$ Saeid Ghavamzadeh ${ }^{2} \cdot$ Ali Shokri $^{1} \cdot$ Laleh Payahoo $^{3} \cdot$ Yaser Khaje Bishak $^{3}$
}

Received: 7 July 2017 / Accepted: 1 December 2017 / Published online: 26 December 2017

(c) The Author(s) 2017. This article is an open access publication

\begin{abstract}
Vitamin D is one of the main groups of sterols; playing an important role in phospho-calcic metabolism. The conversion of 7-dehydrocholesterol to pre- vitamin D3 in the skin, through solar ultraviolet B radiation, is the main source of vitamin D. Since lupus patients are usually photosensitive, the risk of developing vitamin D deficiency in is high in this population. Although evidences showed the connotation between systemic lupus erythematosus (SLE) and vitamin D through which SLE can lead to lower vitamin D levels, it is also important to consider the possibility that vitamin D deficiency may have a causative role in SLE etiology. This paper analyzes existing data from various studies to highlight the role of vitamin D deficiency in SLE occurrence and aggravation and the probable efficacy of vitamin D supplementation on SLE patients. We searched "Science Direct" and "Pub Med" using "Vitamin D" and "SLE" for finding the studies focusing on the association between vitamin D deficiency and SLE incidence and consequences. Evidences show that vitamin D plays an important role in the pathogenesis and progression of SLE and vitamin D supplementation seems to ameliorate inflammatory and hemostatic markers; so, can improve clinical subsequent.
\end{abstract}

Keywords Vitamin D deficiency $\cdot$ Systemic lupus erythematosus $\cdot$ SLE incidence $\cdot$ SLE aggravation

\section{Introduction}

Systemic lupus erythematosus (SLE), a systemic autoimmune disease, can cause chronic inflammation and damage in several tissues and organs [1]. Genetic susceptibility and environmental factors are both responsible for the pathogenesis of SLE [2,3]. Vitamin D deficiency is one of such factors [4]. Vitamin D plays vital role in mineral metabolism, and skeletal, cardiovascular and immune systems health [5]. The prevalence of vitamin D deficiency is high and evidence shows that it can contribute to the morbidity and mortality of numerous chronic diseases, including SLE [5]. As patients

Leila Khalili

leylakhalili1990@gmail.com; khalilil@tbzmed.ac.ir

1 Department of Nutrition, Faculty of Nutrition and Food Sciences, Tabriz University of Medical Sciences, Tabriz, I.R., Iran

2 Department of Human Nutrition, Medicine Faculty, Urmia University of Medical Sciences, Urmia, Iran

3 Talented Student Center, Student Research Committee, Faculty of Nutrition and Food Sciences, Tabriz University of Medical Sciences, Tabriz, I.R., Iran with SLE avoid the sun because of photosensitive rashes and potential for disease flare [5]; adequate vitamin D supplementation is vital for them. The vitamin $\mathrm{D}$ deficiency not only is known as a risk factor [4] of autoimmune diseases such as multiple sclerosis (MS) and type 1 diabetes (T1D) [6], but also can affect disease activity and disease damage in SLE patients [7]. This review is going to summarize the evidences about the effects of vitamin D deficiency in SLE occurrence and/or aggravation and its consequences.

\section{Vitamin D deficiency and SLE}

Vitamin D, as a steroid hormone, exhibits regulatory effects on growth, proliferation, apoptosis and function of the immune system cells that are associated with pathophysiology of SLE [8]. Vitamin D inadequacy is highly prevalent in SLE patients due to the avoidance of sunshine, photoprotection, renal insufficiency and the use of medications such as glucocorticoids, anticonvulsants, antimalarials and the calcineurin inhibitors, which alter the metabolism of vitamin D or down regulate the functions of the vitamin D receptor [8]. Kamen et al. [5] found 
significantly lower serum 25-hydroxyvitamin D levels among recently diagnosed SLE patients compared to matched controls, and a high overall prevalence of vitamin $\mathrm{D}$ deficiency. The deficiency was seen in this population even in the summer, likely due to the use of sunscreens, avoidance of sun exposure, or darker skin pigment and the limited amount of vitamin D obtained from dietary sources [5]. The finding that African Americans and those with photosensitivity had the most severe vitamin D deficiency can be explained with this interpretation [5]. As found by Borba et al. [9] the level of 25OHD and 1,25(OH)2D3 in SLE patients with high activity was lower compared to patients with minimal activity and controls. Only one patient presented the desired 25OHD levels. The possible reason is decreased vitamin $\mathrm{D}$ production because of the lack of sunlight exposure, use of sunblock, or by the disease itself, like the deficiency observed in medical inpatients [10]. Increased metabolism or damaged 25-hydroxylation caused by drugs or even by the disease itself could be another explanation [9].

\section{Vitamin D deficiency and SLE incidence}

Vitamin D regulates the immune system by being involved in interleukin-2 (IL-2) inhibition, antibody production and in lymphocyte proliferation [11-13]. 1,25-dihydroxy vitamin D3 $(1,25(\mathrm{OH}) 2 \mathrm{D} 3)$ inhibits IFN- $\gamma$ secretion and by down-regulating NF- $\kappa \mathrm{B}$ inversely controls IL-12 production [14]. When administered in vivo, $1,25(\mathrm{OH}) 2 \mathrm{D} 3$ was found to have a preventative effect on autoimmune diseases, such as murine lupus [15]. Vitamin D deficiency is commonly reported in systemic lupus erythematosus [16]. The link between vitamin D and SLE is two sided (Fig. 1); so that, SLE may lead to lower vitamin D levels and vitamin D deficiency may have a causative role in SLE etiology and/or aggravation [6]. This perception is accumulating an important evidence base with regard to the matter that vitamin D deficiency is widely known as a risk factor of numerous autoimmune diseases, including MS and type 1 diabetes (T1D) [17]. By measuring serum vitamin D levels in individuals before MS onset, Munger et al. [18] showed that individuals with high $25(\mathrm{OH}) \mathrm{D}$ levels $(100 \mathrm{nmol} / \mathrm{L})$ have

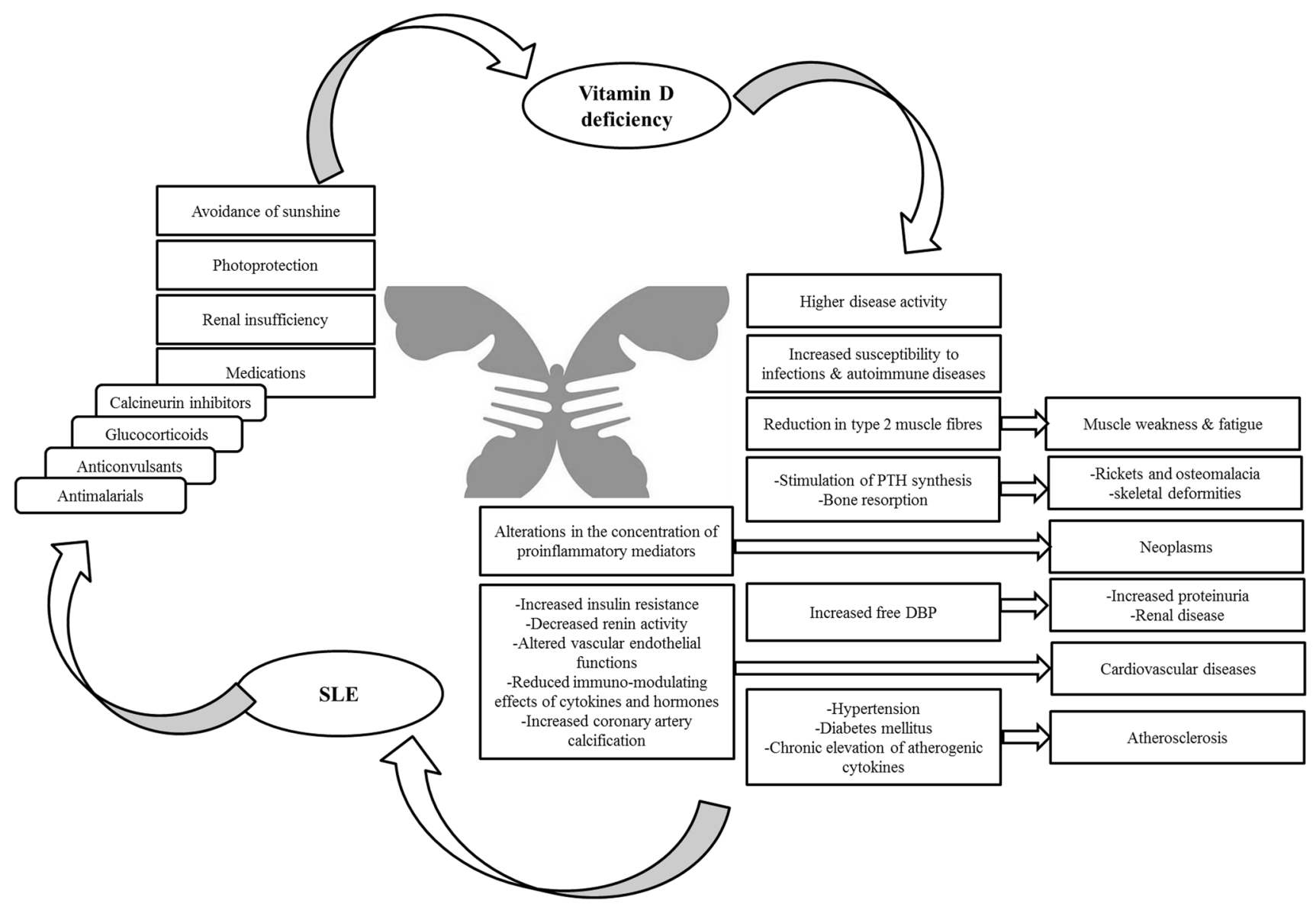

Fig. 1 The two-sided relation between vitamin D and SLE showing that low levels of vitamin D resulted from SLE and SLE complications come from vitamin D deficiency 
a $62 \%$ lower MS risk. In vitro studies showed that 1,25-dihydroxyvitamin $\mathrm{D}$ could prevent differentiation of dendritic cells and modulates $\mathrm{T}$ cell phenotype and function [19]. 1,25-dihydroxy vitamin $\mathrm{D}$ can inhibit $\mathrm{T}$ cell proliferation and cytokine production, inhibit proliferation of activated $\mathrm{B}$ cells, and impair generation of plasma cells [20,21]. Differentiation of dendritic cells and subsequently production of type I interferon is [11] important in the pathogenesis of systemic lupus erythematosus (SLE) [22]. Therefore, by affecting immune system, vitamin D may play a preventive role in SLE incidence.

Establishing the temporal relationship between vitamin $D$ deficiency and preceding disease onset is needed to determine a potentially causal role for vitamin D in SLE [6]. Disanto et al. [23] detected a clear seasonal distribution of beginnings for some of immune-related diseases, including MS and SLE, in which a peak in April and a trough exactly 6 months later in October were found. These findings implicate a varying seasonal factor such as UVB radiation and subsequent vitamin D synthesis in disease etiology. Considering the fact that the genes associated with SLE, MS, and T1D have been enriched for vitamin D receptor binding sites, it can be understood that vitamin D may possibly influence disease risk by regulating the SLE associated genes [24]. The immune modulating effect of vitamin D is established now; thus, it is logical that vitamin D deficiency is a risk factor, rather than a consequence of SLE [6].

Vitamin D activity is dependent on VDR (vitamin D receptor), a member of the nuclear hormone receptor superfamily. The VDR gene is located on chromosome 12q13.11 [25], and three polymorphisms, BsmI, ApaI (both in intron 8), and TaqI (in exon 9), have been identified at the 30-end of the gene [26]. As vitamin D presents immunosuppressive effects and there are potential link between vitamin D deficiency and autoimmune diseases, VDR polymorphisms that can affect VDR activity, have been evaluated as the probable cause of autoimmune diseases [24]. The meta-analysis, conducted by Lee et al. [27] addresses the link between VDR polymorphisms and RA and SLE susceptibility. According to the findings in addition to vitamin $\mathrm{D}$ deficiency, the vitamin D receptor (VDR) polymorphisms can confer susceptibility to immune-related diseases such as rheumatoid arthritis (RA) and systemic lupus erythematous (SLE) [27, 28].

\section{Vitamin D deficiency and SLE consequences}

Low levels of vitamin D that is in relation with SLE activity, are mostly found in SLE patients [29-32]. In comparison with many other cells and tissues that harbor VDR, muscles are one of the most sensitive tissues that vitamin D deficiency causes weakness and fatigue [33, 34]. Moreover, the development of neoplasms and cardiovascular disease, increased susceptibility to infections, and autoimmune diseases are associated with vitamin D deficiency $[33,35]$.

\section{Vitamin $\mathrm{D}$ deficiency and disease activity}

Considering the existence of VDRs on most cells of the immune system, the immunomodulatory effects of vitamin D can be understood [36]. The association between serum concentrations of vitamin $\mathrm{D}$ and the progression and development of autoimmune disorders has been focused on in several studies [37]. It has been revealed that disease activity and autoantibody production in SLE cases may be aggravated by vitamin D insufficiency [36]. Many of the immunomodulatory effects of vitamin D are opposite to the immunological abnormalities observed with disease activity in SLE patients [36]. So, it can be concluded that vitamin D deficiency is a risk factor for the onset and development of disease activity in SLE [36]. A cross-sectional study involving 378 patients with SLE from Europe to the Middle East [37] and the study conducted by Mok et al. [38] showed a significantly opposite relationship between 25 -hydroxyvitamin D3 levels and disease activity scores. In another report, Amital et al. [37] revealed a significant inverse connection between the grade of SLE activity and serum vitamin D concentration. The results indicated that, among other factors, vitamin D deficiency can probably contribute to the progression of active disease in patients with SLE. In the study conducted on a large group of Australian patients with SLE, it had been shown that vitamin D insufficiency was associated with a higher disease activity and a rise in serum vitamin D level was associated with reduced disease activity over time [39]. Furthermore, vitamin D deficiency has been involved in the progression of rickets and osteomalacia, neoplasms and cardiovascular disease as well as in an increased susceptibility to infections and autoimmune diseases [33, 35].

\section{Vitamin D deficiency and fatigue and muscle strength}

As shown in recent studies there is an inverse relationship between vitamin D levels and fatigue in SLE. Individuals with SLE have reduced exercise capacity [40], reduced strength [41], reduced quality of life [42] and elevated levels of fatigue [43]. More than 50\% of people with SLE describe fatigue as the most disabling disease symptom [44]. Vitamin D receptors have been found on muscle cells [45, 46], which proves the theory of the direct effect of vitamin D on muscle tissue. Vitamin D deficiency can cause proximal muscle weakness with a reduction in type 2 muscle fibres [47]. Myositis in SLE is an uncommon but well defined condition with a reduction in strength, elevation in serum CK 
(creatine kinase) and abnormal muscle biopsy results [48]. In a study conducted by Stockton et al. [49] women in the SLE group were weaker in all muscle groups tested except shoulder abduction compared with the control group. The control group reported a median of 2.2 (range 1.0-3.8) on the FSS, which is representative of the reported predicted norm-based scores of 2.3 (0.7) [44]. In comparison, the SLE group reported significantly elevated fatigue of 5.1 (1.6-7.0), which is similar to the other published SLE cohorts $[43,50]$. An observational study that conducted on 80 patients with SLE to evaluate the vitamin D insufficiency and deficiency, recommended oral vitamin D3 in patients with low baseline 25(OH)D levels [51]. The relationship between changes in $25(\mathrm{OH}) \mathrm{D}$ levels from baseline to changes in fatigue (measured by a $0-10$ visual analog scale [VAS]) was analyzed. An inverse correlations was found between $25(\mathrm{OH}) \mathrm{D}$ levels and the VAS and between changes in $25(\mathrm{OH}) \mathrm{D}$ levels and changes in the VAS in patients with baseline 25(OH)D levels $30 \mathrm{ng} / \mathrm{mL}$. It was recognized that increasing $25(\mathrm{OH}) \mathrm{D}$ levels may have a positive effect on fatigue. According to several researches dose adjustments should be based on monitoring of serum $25(\mathrm{OH}) \mathrm{D}$ levels [51]. In the general population, levels above $30 \mathrm{ng} / \mathrm{mL}$ are the recommended goal to avoid parathyroid hormone activation [33]. However, it is not clear whether these are the optimal levels in patients with lupus [51]. Ruiz-Irastorza et al. [51] recommended the use of dosages of vitamin D3 higher than 800 IU/day for SLE patients with vitamin $\mathrm{D}$ insufficiency or deficiency.

\section{Vitamin D deficiency and bone disease and fracture}

Improving the intestinal absorption and renal resorption of calcium to increase its circulating levels that is mediated by the interactions between vitamin D and vitamin D receptors (VDRs) is the main metabolic effect of $1,25(\mathrm{OH}) 2 \mathrm{D}$ $[33,52]$. Stimulation of PTH synthesis and bone resorption can be caused as the result of low levels of vitamin D. Continuance insufficiency of vitamin D results in rickets and osteomalacia, with skeletal deformities in children and bone pain and increased risk of fractures in adults [33]. The risk of osteoporosis and bone fractures is higher in patients with SLE [53]. Several factors are involved in the pathophysiology of bone disease in SLE, including environmental and hormonal factors, medications, inflammatory process, renal disease, and vitamin D deficiency as the result of photosensitivity [30, 32, 53-56]. Furthermore, alterations in the concentration of proinflammatory mediators have been described in SLE patients such as cytokines known by their potential role on bone metabolism [57, 58]. SLE patients are at high risk for fracture, even if with normal BMD values [9]. Recent meta-analyses showed that higher-dose vitamin
D intake could reduce fall risk by $19 \%$ and fracture risk by $15-29 \%$ [59]. Considering the evidences, it is vital to evaluate vitamin D deficiency and to correct the vitamin D nutritional status in SLE subjects [9].

\section{Vitamin $\mathrm{D}$ deficiency and renal diseases}

According to the researches there is a connotation between vitamin D deficiency and SLE renal disorders [32]. In a clinical trial conducted by Robinson et al. [60] serum $25(\mathrm{OH})$ $\mathrm{D}$ levels in patients with SLE were directly connected with serum albumin and inversely connected with the UP/C ratio and urinary DBP/C. A review of subjects with pediatric SLE revealed an association between proliferative SLE glomerulonephritis and vitamin D deficiency, and an average 10-ng/ $\mathrm{mL}$ difference in serum $25(\mathrm{OH}) \mathrm{D}$ levels between subjects with and without nephritis [61]. Low serum 25(OH)D levels would decrease the amount of $25(\mathrm{OH}) \mathrm{D}$ bound to the DBP that is spilled in urine. DBP loss in urine may reflect the magnitude of proteinuria shown by SLE patients [60]. It has been found that a $20 \mathrm{ng} / \mathrm{mL}$ increase in vitamin $\mathrm{D}$ was associated with a $21 \%$ decrease in the probability of having a high activity score and a $15 \%$ decrease in the possibility of having clinically important proteinuria [62]. Studies on patients with stage 3 and 4 chronic kidney disease showed that the reduction in proteinuria in the paricalcitol (a vitamin D compound) treated patients was 3.2 times greater in comparison with the placebo group [63]. More researches are needed to evaluate the relationship among vitamin D deficiency in SLE patients and renal diseases.

\section{Vitamin D deficiency and cardiovascular diseases}

As shown by evidences, vitamin D deficiency is associated with cardiovascular disease [38]. Observational studies have revealed a connotation between low 25(OH)D3 level and stroke, myocardial infarction, hypertensive heart disease, obesity, dyslipidemia, and diabetes mellitus [64-67]. Some of the suggested mechanisms for the adverse effects of vitamin D deficiency on the cardiovascular system include increased peripheral resistance to insulin, decreased renin activity, altered vascular endothelial functions, reduced immuno-modulating effects of cytokines and hormones such as IL-10, TNF- $\alpha$, and PTH, and increased coronary artery calcification [68]. According to the third National Health and Nutrition Examination Survey (NHANES III) [69] patients within the lowest vitamin D level $(20 \mathrm{ng} / \mathrm{mL})$, had a significantly increased prevalence of selected CVD risk factors (including a history of diabetes and elevated 


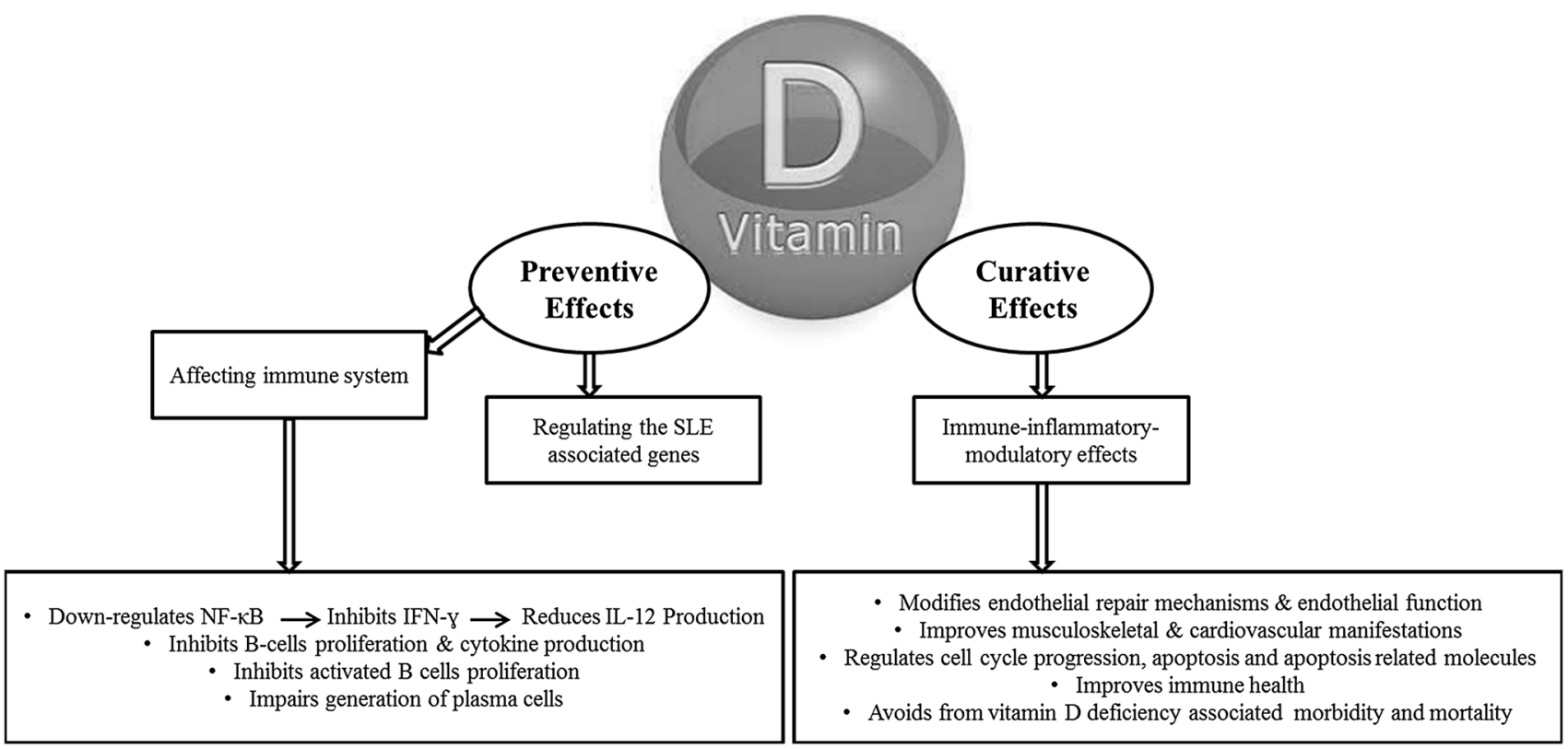

Fig. 2 The beneficial effects of vitamin D in prevention and/or control of SLE

blood pressure, fasting blood glucose, BMI and triglycerides) when compared with the highest level $(37 \mathrm{ng} / \mathrm{mL})$.

Due to the increased prevalence of the traditional risk factors such as hypertension, diabetes mellitus, and chronic elevation of atherogenic cytokines, patients with SLE are at risk of atherosclerosis [70]. A Recent research showed that hypovitaminosis D in SLE patients was associated with increased fasting glucose level [71]. Mok et al. [38] showed a significant inverse relationship between the levels of 25(OH)D3 and SLE disease activity scores. Vitamin D deficiency was connected with higher LDL cholesterol and lower HDL cholesterol, higher triglyceride level, the presence of aPLs, and premenopausal status. Similarly, Ezzat et al. [72] revealed that there is an association between lower 25(OH)D levels and increased CVD risk factors, as well as increased SLE disease activity and damage indices, also with the presence of proteinuria, low complement levels and steroid use. More studies are needed to understand whether vitamin D levels can predict the progression of subclinical atherosclerosis as measured by imaging markers as well as cardiovascular events in patients with lupus.

\section{Vitamin $D$ deficiency and malignancy}

It has been proved that the risk of developing many chronic illnesses especially common cancers would be decreased by vitamin D [16]. Serum levels of 25(OH)D lower than $20 \mathrm{ng} / \mathrm{mL}$ among the general population is connected with an increased risk of dying from colon, ovarian, breast, and prostate cancer [33]. As mentioned before Vitamin D deficiency that is common in SLE, has been associated with cardiovascular disease, diabetes mellitus, and certain forms of cancer [73]. Vitamin D and its metabolites decrease the incidence of several types of cancer by stimulating mutual adherence of cells, inhibiting tumor angiogenesis [74-76], and enhancing intercellular communication through gap junctions [77], so strengthening the inhibition of proliferation that results from tight physical contact with adjacent cells within a tissue [78]. The metabolites of vitamin $\mathrm{D}$ help to the maintenance of the normal calcium gradient in the colon epithelial crypts [79], and high serum levels of $25(\mathrm{OH}) \mathrm{D}$ are connected with decreased proliferation of noncancerous but high-risk epithelial cells in the colon [80]. 1,25(OH)2D inhibits mitosis of breast epithelial cells [81]. Pulsatile release of ionized calcium from intracellular stores, including the endoplasmic reticulum, induces terminal differentiation and apoptosis [82], and 1,25(OH)2D improves this release [83]. It has been shown that the administration of 1100 IU of vitamin D daily over 4 years will reduce allcancer risk in postmenopausal females [84]. A meta-analysis of 18 randomized controlled trials showed that subjects randomized to vitamin D supplementation experienced fewer deaths in comparison with those randomized to placebo [85]. Further investigations are needed to determine if vitamin D supplements can prevent the incidence of certain cancers in SLE patients. 


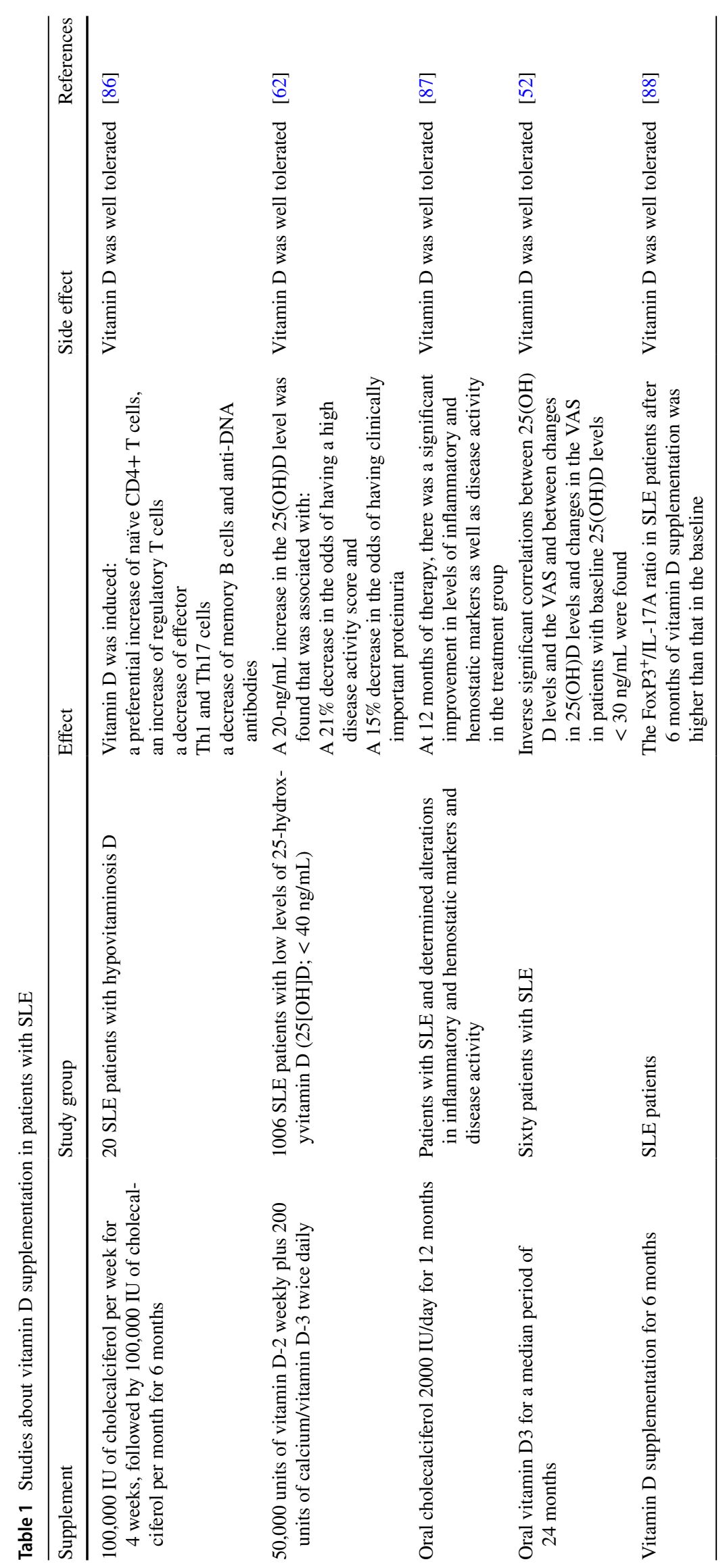




\section{Role of vitamin D supplementation in SLE improvement}

Vitamin D is a safe and inexpensive agent that is widely available. It could be beneficial as a disease suppressing intervention for SLE patients [5]. Besides its potential benefit in improvement of SLE activity, vitamin D is known to present immune-inflammatory-modulatory effect that can benefit musculoskeletal and cardiovascular manifestations of SLE. This role could also help maintain immune health; so, avoiding the excess vitamin $\mathrm{D}$ deficiency related morbidity and mortality [5] (Fig. 2). Recent evidences have shown the potential benefit of vitamin $D$ supplementation in SLE patients (Table 1) [52, 62, 86-88]. Tabasi et al. [89] isolated peripheral blood mononuclear cells (PBMCs) from 25 SLE patients and cultured them in the presence of $50 \mathrm{nM}$ of $1,25(\mathrm{OH}) 2 \mathrm{D} 3$. The results showed that Vitamin D has regulatory effects on cell cycle progression, apoptosis and apoptosis related molecules in lupus patients. The results of the investigation conducted by Reynolds et al. [90] demonstrate that vitamin D can positively modify endothelial repair mechanisms and so endothelial function in SLE patients that are susceptible for cardiovascular diseases. Abou-Raya et al. [87] showed an inverse association between 25(OH) $\mathrm{D}$ levels and disease activity markers. The observed that 25(OH)D levels were lowest among patients with active SLE. It was revealed that vitamin D deficiency could result in increased activity in SLE patients. Moreover, they found an improvement in the levels of proinflammatory cytokines after 12 months of vitamin D supplementation compared to placebo [87]. Early vitamin D supplementation in animal SLE models presented immunomodulatory effects [62] for instance dermatologic lesions, proteinuria, and anti-DNA were lesser in MRL/l mice supplemented with vitamin D [91].

It should be noted that vitamin D supplementation could not always be completely safe. Vitamin D toxicity can cause by excessive oral supplementation [92]. The most important complications are hypercalciuria and hypercalcemia, however, hypercalcemia is mainly seen when the serum vitamin D levels reach $220 \mathrm{nmol} / \mathrm{L}$ and is most frequent when over $500 \mathrm{nmol} / \mathrm{L}$ [93] and the symptoms of hypercalcemia (nausea, vomiting, diarrhea, and headache) and renal stones appear in vitamin $D$ intoxicated patients. It would be better to measure the baseline vitamin D level before supplementation. The Australian position statement on vitamin D in adults expresses that considering the individual variation of response to vitamin D supplementation, vitamin D levels are checked after 3 months [94]. Currently, there is no international consensus on the optimal dose for supplementation of vitamin D. European Food and Safety Authority recommends supplementation below 4000 IU/day [95]. Vitamin
D supplementation in SLE patients is recommended as the increased vitamin D levels can ameliorate inflammatory and hemostatic markers and potentially clinical improvement [87]. Newly, 'preventive' treatment with vitamin D of subjects considered at high risk for developing autoimmune diseases has been suggested [28].

\section{Conclusion}

Patients with SLE are at a clear risk of developing $25(\mathrm{OH})$ $\mathrm{D}$ deficiency because of photosensitivity and the frequently use of photoprotection [28]. In addition to the potential benefit of vitamin D replacement on SLE activity, patients will also avoid the excess morbidity and mortality associated with vitamin D deficiency [5]. More researches will help us better understand the role of vitamin $\mathrm{D}$ as immunomodulatory and determine the ideal range of serum $25(\mathrm{OH}) \mathrm{D}$ for musculoskeletal, cardiovascular, and immune health. Since vitamin $\mathrm{D}$ has an immune modulating effect, it is plausible that vitamin D deficiency is not only a risk factor, but also a consequence of SLE. According to several trials routine assessment of vitamin D levels and adequate supplementation of the vitamin in patients with SLE is recommended [5]. However, further large-scale studies are needed to establish the desired level of supplementation for prevention and/or improvement of SLE.

\section{Compliance with ethical standards}

Conflict of interest The authors declare that they have no conflict of interest.

Informed consent There is no informed consent required for this manuscript.

Human and animal rights There are no human or animal rights to be considered in this manuscript.

Open Access This article is distributed under the terms of the Creative Commons Attribution 4.0 International License (http://creativecomm ons.org/licenses/by/4.0/), which permits unrestricted use, distribution, and reproduction in any medium, provided you give appropriate credit to the original author(s) and the source, provide a link to the Creative Commons license, and indicate if changes were made.

\section{References}

1. Agmon-Levin N, Mosca M, Petri M, Shoenfeld Y (2012) Systemic lupus erythematosus one disease or many? Autoimmun Rev 11:593-595

2. Fu SM, Deshmukh US, Gaskin F (2011) Pathogenesis of systemic lupus erythematosus revisited 2011: end organ resistance to 
damage, autoantibody initiation and diversification, and HLA-DR. J Autoimmun 37:104-112

3. Borchers AT, Naguwa SM, Shoenfeld Y, Gershwin ME (2010) The geoepidemiology of systemic lupus erythematosus. Autoimmun Rev 9:A277-A287

4. Yang C-Y, Leung PS, Adamopoulos IE, Gershwin ME (2013) The implication of vitamin D and autoimmunity: a comprehensive review. Clin Rev Allergy Immunol 45:217-226

5. Kamen DL (2010) Vitamin D in lupus: new kid on the block? Bull Hosp Jt Dis 68:218

6. Pakpoor J, Pakpoor J (2013) Vitamin d deficiency and systemic lupus erythematosus: cause or consequence. Oman Med J 28:295

7. Sakthiswary R, Raymond AA (2013) The clinical significance of vitamin D in systemic lupus erythematosus: a systematic review. PLoS One 8:e55275

8. Mok CC (2013) Vitamin D and systemic lupus erythematosus: an update. Expert Rev Clin Immunol 9:453-463

9. Borba V, Vieira J, Kasamatsu T, Radominski S, Sato E, LazarettiCastro M (2009) Vitamin D deficiency in patients with active systemic lupus erythematosus. Osteoporis Int 20:427-433

10. Thomas MK, Lloyd-Jones DM, Thadhani RI, Shaw AC, Deraska DJ, Kitch BT et al (1998) Hypovitaminosis D in medical inpatients. N Engl J Med 338:777-783

11. Maruotti N, Cantatore FP (2010) Vitamin D and the immune system. J Rheumatol 37:491-495

12. Iruretagoyena M, Hirigoyen D, Naves R, Burgos PI (2015) Immune response modulation by vitamin D: role in systemic lupus erythematosus. Front Immunol 6:513

13. Cutolo M, Otsa K, Paolino S, Yprus M, Veldi T, Seriolo B (2009) Vitamin D involvement in rheumatoid arthritis and systemic lupus erythaematosus. Ann Rheum Dis 68:446

14. Boonstra A, Barrat FJ, Crain C, Heath VL, Savelkoul HF, O' Garra A (2001) 1 $\alpha, 25$-Dihydroxyvitamin D3 has a direct effect on naive CD4+ T cells to enhance the development of Th2 cells. J Immunol 167:4974-4980

15. Koizumi T, Nakao Y, Matsui T, Nakagawa T, Matsuda S, Komoriya $\mathrm{K}$ et al (1985) Effects of corticosteroid and 1,24R-dihydroxy-vitamin D3 administration on lymphoproliferation and autoimmune disease in MRL/MP-lpr/lpr mice. Int Arch Allergy Immunol 77:396-404

16. Attar SM, Siddiqui AM (2013) Vitamin d deficiency in patients with systemic lupus erythematosus. Oman Med J 28:42-47

17. Handel AE, Handunnetthi L, Ebers GC, Ramagopalan SV (2009) Type 1 diabetes mellitus and multiple sclerosis: common etiological features. Nat Rev Endocrinol 5:655-664

18. Munger KL, Levin LI, Hollis BW, Howard NS, Ascherio A (2006) Serum 25-hydroxyvitamin D levels and risk of multiple sclerosis. JAMA 296:2832-2838

19. Penna G, Adorini L (2000) 1 1 ,25-dihydroxyvitamin D3 inhibits differentiation, maturation, activation, and survival of dendritic cells leading to impaired alloreactive $\mathrm{T}$ cell activation. J Immunol 164:2405-2411

20. Chen S, Sims GP, Chen XX, Gu YY, Chen S, Lipsky PE (2007) Modulatory effects of 1,25-dihydroxyvitamin D3 on human B cell differentiation. J Immunol 179:1634-1647

21. Van Halteren AG, Tysma OM, van Etten E, Mathieu C, Roep BO (2004) $1 \alpha, 25$-Dihydroxyvitamin D 3 or analogue treated dendritic cells modulate human autoreactive $\mathrm{T}$ cells via the selective induction of apoptosis. J Autoimmun 23:233-239

22. Rönnblom L, Pascual V (2008) The innate immune system in SLE: type I interferons and dendritic cells. Lupus 17:394-399

23. Disanto G, Chaplin G, Morahan JM, Giovannoni G, Hyppönen E, Ebers GC et al (2012) Month of birth, vitamin D and risk of immune-mediated disease: a case control study. BMC Med 10:1

24. Ramagopalan SV, Heger A, Berlanga AJ, Maugeri NJ, Lincoln MR, Burrell A et al (2010) A ChIP-seq defined genome-wide map of vitamin D receptor binding: associations with disease and evolution. Genome Res 20:1352-1360

25. K-i Miyamoto, Kesterson RA, Yamamoto H, Taketani Y, Nishiwaki E, Tatsumi S et al (1997) Structural organization of the human vitamin D receptor chromosomal gene and its promoter. Mol Endocrinol 11:1165-1179

26. Morrison NA, Yeoman R, Kelly PJ, Eisman JA (1992) Contribution of trans-acting factor alleles to normal physiological variability: vitamin D receptor gene polymorphism and circulating osteocalcin. Proc Natl Acad Sci 89:6665-6669

27. Lee YH, Bae S-C, Choi SJ, Ji JD, Song GG (2011) Associations between vitamin D receptor polymorphisms and susceptibility to rheumatoid arthritis and systemic lupus erythematosus: a meta-analysis. Mol Biol Rep 38:3643-3651

28. Ruiz-Irastorza G, Egurbide M, Olivares N, Martinez-Berriotxoa A, Aguirre C (2008) Vitamin D deficiency in systemic lupus erythematosus: prevalence, predictors and clinical consequences. Rheumatology 47:920-923

29. Bultink IE, Lems WF, Kostense PJ, Dijkmans BA, Voskuyl AE (2005) Prevalence of and risk factors for low bone mineral density and vertebral fractures in patients with systemic lupus erythematosus. Arthritis Rheum 52:2044-2050

30. Müller K, Kriegbaum N, Baslund B, Sørensen O, Thymann M, Bentzen K (1995) Vitamin D3 metabolism in patients with rheumatic diseases: low serum levels of 25-hydroxyvitamin D3 in patients with systemic lupus erythematosus. Clin Rheumatol $14: 397-400$

31. Huisman AM, White KP, Algra A, Harth M, Vieth R, Jacobs $\mathrm{J}$ et al (2001) Vitamin D levels in women with systemic lupus erythematosus and fibromyalgia. J Rheumatol 28:2535-2539

32. Kamen DL, Cooper GS, Bouali H, Shaftman SR, Hollis BW, Gilkeson GS (2006) Vitamin D deficiency in systemic lupus erythematosus. Autoimmun Rev 5(2):114-117

33. Holick MF (2007) Vitamin D deficiency. N Engl J Med 357:266-281

34. Janssen HC, Samson MM, Verhaar HJ (2002) Vitamin D deficiency, muscle function, and falls in elderly people. Am J Clin Nutr 75:611-615

35. Holick MF (2004) Vitamin D: importance in the prevention of cancers, type 1 diabetes, heart disease, and osteoporosis. Am J Clin Nutr 79:362-371

36. Mok C, Birmingham D, Ho L, Hebert L, Song H, Rovin B (2012) Vitamin D deficiency as marker for disease activity and damage in systemic lupus erythematosus: a comparison with anti-dsDNA and anti-C1q. Lupus 21:36-42

37. Amital H, Szekanecz Z, Szücs G, Danko K, Nagy E, Csepany $T$ et al (2010) Serum concentrations of $25-\mathrm{OH}$ vitamin D in patients with systemic lupus erythematosus (SLE) are inversely related to disease activity: is it time to routinely supplement patients with SLE with vitamin D? Ann Rheum Dis 69:1155-1157

38. Mok CC, Birmingham DJ, Leung HW, Hebert LA, Song H, Rovin BH (2012) Vitamin D levels in Chinese patients with systemic lupus erythematosus: relationship with disease activity, vascular risk factors and atherosclerosis. Rheumatology 51:644-652

39. Yap K, Northcott M, Hoi AB, Morand E, Nikpour M (2015) Association of low vitamin $\mathrm{D}$ with high disease activity in an Australian systemic lupus erythematosus cohort. Lupus Sci Med 2:e000064

40. Holick MF (2006) High prevalence of vitamin D inadequacy and implications for health. Mayo Clin Proc 81:353-373

41. Tench C, McCurdie I, McCarthy J, White P, D’Cruz D (1998) The assessment of aerobic capacity in a group of patients with SLE and its association with fatigue, sleep quality and disease activity. Arthritis Rheum 9:S332 
42. Ramsey-Goldman R, Schilling EM, Dunlop D, Langman C, Greenland P, Thomas RJ et al (2000) A pilot study on the effects of exercise in patients with systemic lupus erythematosus. Arthr Care Res 13:262-269

43. Kiani AN, Petri M (2010) Quality-of-life measurements versus disease activity in systemic lupus erythematosus. Curr Rheumatol Rep 12:250-258

44. Zonana-Nacach A, Roseman JM, McGwin G, Friedman AW, Baethge BA, Reveille JD (2000) Systemic lupus erythematosus in three ethnic groups. VI: factors associated with fatigue within 5 years of criteria diagnosis. Lupus 9:101-109

45. Krupp LB, LaRocca NG, Muir-Nash J, Steinberg AD (1989) The fatigue severity scale: application to patients with multiple sclerosis and systemic lupus erythematosus. Arch Neurol 46:1121-1123

46. Bischoff H, Borchers M, Gudat F, Duermueller U, Theiler R, Stähelin $\mathrm{H}$ et al (2001) In situ detection of 1,25-dihydroxyvitamin D receptor in human skeletal muscle tissue. Histochem J 33:19-24

47. Simpson R, Thomas G, Arnold A (1985) Identification of 1,25-dihydroxyvitamin D3 receptors and activities in muscle. $\mathrm{J}$ Biol Chem 260:8882-8891

48. Sato Y, Iwamoto J, Kanoko T, Satoh K (2005) Low-dose vitamin $\mathrm{D}$ prevents muscular atrophy and reduces falls and hip fractures in women after stroke: a randomized controlled trial. Cerebrovasc Dis 20:187-192

49. Finol H, Montagnani S, Marquez A, Montes DO, Müller B (1990) Ultrastructural pathology of skeletal muscle in systemic lupus erythematosus. J Rheumatol 17:210-219

50. Stockton K, Kandiah D, Paratz JD, Bennell K (2012) Fatigue, muscle strength and vitamin D status in women with systemic lupus erythematosus compared with healthy controls. Lupus 21:271-278

51. Tench C, McCurdie I, White P, D'Cruz D (2000) The prevalence and associations of fatigue in systemic lupus erythematosus. Rheumatology 39:1249-1254

52. Ruiz-Irastorza G, Gordo S, Olivares N, Egurbide MV, Aguirre C (2010) Changes in vitamin D levels in patients with systemic lupus erythematosus: effects on fatigue, disease activity, and damage. Arthr Care Res 62:1160-1165

53. Rhew EY, Lee C, Eksarko P, Dyer AR, Tily H, Spies S et al (2008) Homocysteine, bone mineral density, and fracture risk over 2 years of followup in women with and without systemic lupus erythematosus. J Rheumatol 35:230-236

54. Kalla AA, Fataar AB, Jessop SJ, Bewerunge L (1993) Loss of trabecular bone mineral density in systemic lupus erythematosus. Arthr Rheum 36:1726-1734

55. Cunnane G, Lane NE (2000) Steroid-induced osteoprosis in systemic lupus erythematosus. Rheum Dis Clin N Am 26:311-329

56. Sen D, Keen R (2001) Osteoporosis in systemic lupus erythematosus: prevention and treatment. Lupus 10:227-232

57. Aringer M, Smolen J (2004) Tumour necrosis factor and other proinflammatory cytokines in systemic lupus erythematosus: a rationale for therapeutic intervention. Lupus 13:344-347

58. Gabay C, Cakir N, Moral F, Roux-Lombard P, Meyer O, Dayer J et al (1997) Circulating levels of tumor necrosis factor soluble receptors in systemic lupus erythematosus are significantly higher than in other rheumatic diseases and correlate with disease activity. J Rheumatol 24:303-308

59. Bischoff-Ferrari HA, Shao A, Dawson-Hughes B, Hathcock J, Giovannucci E, Willett WC (2010) Benefit-risk assessment of vitamin D supplementation. Osteoporis Int 21:1121-1132

60. Robinson AB, Thierry-Palmer M, Gibson KL, Rabinovich CE (2012) Disease activity, proteinuria, and vitamin D status in children with systemic lupus erythematosus and juvenile dermatomyositis. J Pediatr 160:297-302

61. Robinson AB, Rabinovich CE (2008) Hypovitaminosis D is prevalent despite vitamin $\mathrm{D}$ supplementation in pediatric systemic lupus erythematosus. In: Robinson AB, Rabinovich CE (eds) Arthritis Rheumatism, 58th edn., p 3982

62. Petri M, Bello KJ, Fang H, Magder LS (2013) Vitamin D in systemic lupus erythematosus: modest association with disease activity and the urine protein-to-creatinine ratio. Arthr Rheum 65:1865-1871

63. Agarwal R, Acharya M, Tian J, Hippensteel RL, Melnick JZ, Qiu $P$ et al (2005) Antiproteinuric effect of oral paricalcitol in chronic kidney disease. Kidney Int 68:2823-2828

64. Anderson JL, May HT, Horne BD, Bair TL, Hall NL, Carlquist JF et al (2010) Relation of vitamin D deficiency to cardiovascular risk factors, disease status, and incident events in a general healthcare population. Am J Cardiol 106:963-968

65. Kim DH, Sabour S, Sagar UN, Adams S, Whellan DJ (2008) Prevalence of hypovitaminosis D in cardiovascular diseases (from the National Health and Nutrition Examination Survey 2001 to 2004). Am J Cardiol 102:1540-1544

66. Baz-Hecht M, Goldfine AB (2010) The impact of vitamin D deficiency on diabetes and cardiovascular risk. Curr Opin Endocrinol Diabetes Obes 17:113-119

67. Martins D, Wolf M, Pan D, Zadshir A, Tareen N, Thadhani $R$ et al (2007) Prevalence of cardiovascular risk factors and the serum levels of 25-hydroxyvitamin D in the United States: data from the Third National Health and Nutrition Examination Survey. Arch Intern Med 167:1159-1165

68. Vanga SR, Good M, Howard PA, Vacek JL (2010) Role of vitamin D in cardiovascular health. Am J Cardiol 106:798-805

69. Hochberg MC (1997) Updating the American College of Rheumatology revised criteria for the classification of systemic lupus erythematosus. Arthr Rheum 40:1725

70. Mok C (2006) Accelerated atherosclerosis, arterial thromboembolism, and preventive strategies in systemic lupus erythematosus. Scand J Rheumatol 35:85-95

71. Wu PW, Rhew EY, Dyer AR, Dunlop DD, Langman CB, Price $\mathrm{H}$ et al (2009) 25-hydroxyvitamin D and cardiovascular risk factors in women with systemic lupus erythematosus. Arthr Care Res 61:1387-1395

72. Ezzat Y, Sayed S, Gaber W, Mohey AM, Kassem TW (2011) 25-Hydroxy vitamin D levels and its relation to disease activity and cardiovascular risk factors in women with systemic lupus erythematosus. Egypt Rheumatol 33:195-201

73. Petri M, Bello KJ (2010) Vitamin D levels are positively associated with complement among patients with SLE. Arthritis Rheum 62:1180

74. Iseki K, Tatsuta M, Uehara H, Iishi H, Yano H, Sakai $\mathrm{N}$ et al (1999) Inhibition of angiogenesis as a mechanism for inhibition by L $\alpha$-hydroxyvitamin D3 and 1,25-dihydroxyvitamin D3 of colon carcinogenesis induced by azoxymethane in Wistar rats. Int J Cancer 81:730-733

75. Mantell D, Owens P, Bundred N, Mawer E, Canfield A (2000) $1 \alpha, 25$-dihydroxyvitamin D3 inhibits angiogenesis in vitro and in vivo. Circ Res 87:214-220

76. Pálmer HG, González-Sancho JM, Espada J, Berciano MT, Puig I, Baulida J et al (2001) Vitamin D3 promotes the differentiation of colon carcinoma cells by the induction of E-cadherin and the inhibition of $\beta$-catenin signaling. J Cell Biol 154:369-388

77. Fujioka T, Suzuki Y, Okamoto T, Mastushita N, Hasegawa M, Omori S (2000) Prevention of renal cell carcinoma by active vitamin D3. World J Surg 24:1205-1210

78. Garland CF, Garland FC, Gorham ED, Lipkin M, Newmark H, Mohr SB et al (2006) The role of vitamin D in cancer prevention. Am J Public Health 96:252-261

79. Lipkin M, Newmark H (1985) Effect of added dietary calcium on colonic epithelial-cell proliferation in subjects at high risk for familial colonic cancer. N Engl J Med 313:1381-1384 
80. Holt PR, Arber N, Halmos B, Forde K, Kissileff H, McGlynn KA et al (2002) Colonic epithelial cell proliferation decreases with increasing levels of serum 25-hydroxy vitamin D. Cancer Epidemiol Biomark Prev 11:113-119

81. Campbell MJ, Reddy GS, Koeffler HP (1997) Vitamin D3 analogs and their 24-Oxo metabolites equally inhibit clonal proliferation of a variety of cancer cells but have differing molecular effects. J Cell Biochem 66:413-425

82. Brenner B, Russell N, Albrecht S, Davies R (1998) The effect of dietary vitamin D 3 on the intracellular calcium gradient in mammalian colonic crypts. Cancer Lett 127:43-53

83. Mathiasen IS, Sergeev IN, Bastholm L, Elling F, Norman AW, Jäättelä M (2002) Calcium and calpain as key mediators of apoptosis-like death induced by vitamin $\mathrm{D}$ compounds in breast cancer cells. J Biol Chem 277:30738-30745

84. Lappe JM, Travers-Gustafson D, Davies KM, Recker RR, Heaney RP (2007) Vitamin D and calcium supplementation reduces cancer risk: results of a randomized trial. Am J Clin Nutr 85:1586-1591

85. Autier P, Gandini S (2007) Vitamin D supplementation and total mortality: a meta-analysis of randomized controlled trials. Arch Intern Med 167:1730-1737

86. Terrier B, Derian N, Schoindre Y, Chaara W, Geri G, Zahr N et al (2012) Restoration of regulatory and effector $\mathrm{T}$ cell balance and $\mathrm{B}$ cell homeostasis in systemic lupus erythematosus patients through vitamin D supplementation. Arthr Res Ther 14:1

87. Abou-Raya A, Abou-Raya S, Helmii M (2013) The effect of vitamin D supplementation on inflammatory and hemostatic markers and disease activity in patients with systemic lupus erythematosus: a randomized placebo-controlled trial. J Rheumatol 40:265-272

88. Marinho A, Carvalho C, Boleixa D, Bettencourt A, Leal B, Guimarães J, et al. (2016) Vitamin D supplementation effects on FoxP3 expression in T cells and FoxP3 +/IL-17A ratio and clinical course in systemic lupus erythematosus patients: a study in a Portuguese cohort. Immunol Res 65:1-10

89. Tabasi N, Rastin M, Mahmoudi M, Ghoryani M, Mirfeizi Z, Rabe SZT et al (2015) Influence of vitamin D on cell cycle, apoptosis, and some apoptosis related molecules in systemic lupus erythematosus. Iran J Basic Med Sci 18:1107

90. Reynolds JA, Haque S, Williamson K, Ray DW, Alexander MY, Bruce IN (2016) Vitamin D improves endothelial dysfunction and restores myeloid angiogenic cell function via reduced CXCL-10 expression in systemic lupus erythematosus. Sci Rep 2016:6

91. Lemire JM, Ince A, Takashima M (1992) 1,25-dihydroxyvitamin D3 attenuates of expression of experimental murine lupus of MRL/1 mice. Autoimmunity 12:143-148

92. Yap KS, Morand EF (2015) Vitamin D and systemic lupus erythematosus: continued evolution. Int J Rheum Dis 18:242-249

93. Vieth R (1999) Vitamin D supplementation, 25-hydroxyvitamin D concentrations, and safety. Am J Clin Nutr 69:842-856

94. Nowson CA, McGrath JJ, Ebeling PR, Haikerwal A, Daly RM, Sanders KM et al (2012) Vitamin D and health in adults in Australia and New Zealand: a position statement. Med J Aust 196:686-687

95. Vero V, Gasbarrini A (2012) The EFSA health claims 'learning experience'. Int J Food Sci Nutr 63:14-16 